Revue d'histoire de l'Amérique française

TEYUE D.HISTOIRE DE L'AMÉRIQUE FRANÇAISE

\title{
LAMONDE, Yvan et Raymond MONTPETIT, Le parc Sohmer de Montréal 1889-1919. Un lieu populaire de culture urbaine. Québec, Institut québécois de recherche sur la culture, 1986. 231 p.
}

\section{Gilles Pronovost}

Volume 41, numéro 1, été 1987

URI : https://id.erudit.org/iderudit/304533ar

DOI : https://doi.org/10.7202/304533ar

Aller au sommaire du numéro

Éditeur(s)

Institut d'histoire de l'Amérique française

ISSN

0035-2357 (imprimé)

1492-1383 (numérique)

Découvrir la revue

Citer ce compte rendu

Pronovost, G. (1987). Compte rendu de [LAMONDE, Yvan et Raymond MONTPETIT, Le parc Sohmer de Montréal 1889-1919. Un lieu populaire de culture urbaine. Québec, Institut québécois de recherche sur la culture, 1986. 231 p.] Revue d'histoire de l'Amérique française, 41(1), 93-95.

https://doi.org/10.7202/304533ar d'utilisation que vous pouvez consulter en ligne. 
LAMONDE, Yvan et Raymond MONTPETIT, Le parc Sohmer de Montréal 1889-1919. Un lieu populaire de culture urbaine. Québec, Institut québécois de recherche sur la culture, 1986. $231 \mathrm{p}$.

Cet ouvrage bien fait et bien documenté consiste en une monographie portant sur ce qui a sans doute été le parc urbain le plus important à la fin du siècle dernier à Montréal. La «vie» du parc s'étend en fait de 1889 à 1919 
alors qu'un incendie mit un terme à ce qui était devenu à ce moment un parc en net déclin.

L'histoire de Montréal, voire du Québec, au 19e siècle s'articule autour des grands moments classiques, tels l'industrialisation, les migrations urbaines, les transformations du pouvoir, l'histoire politique, etc. Les mutations de la culture populaire traditionnelle ont moins fait l'objet d'études poussées. Pour le dire un peu rapidement, il nous manque encore une sorte d'histoire culturelle du Québec des 19e et 20e siècles (je songe tout particulièrement aux travaux de Maurice Crubellier en France). Non pas une histoire de la culture savante, telle que la rapportent en raccourci les auteurs de l'Histoire du Québec contemporain; non pas une suite d'anecdotes savoureuses ou burlesques, non plus que la collection des images saintes et des croix de chemin.

Comment a été vécue l'introduction progressive des médias modernes, particulièrement la presse à grand tirage et le cinéma? Quels changements suppose dans les modes de contrôle social l'arrivée de ces nouveaux moyens de communication? Comment ont été progressivement structurés les temps sociaux, comment s'est faite la structuration de l'espace urbain autour de nouveaux lieux de travail et de loisir? Quels ont été les acteurs dominants dans la mise en place des nouvelles formes de culture populaire? Comment se sont articulés les nouveaux rapports homme-femme dans le contexte des nouvelles adaptations familiales? Quelle signification donner aux vastes mouvements de migration? Est-il pertinent ou non de parler de «culture urbaine» en formation?

Yvan Lamonde et Raymond Montpetit n'ont certes pas la prétention d'aborder de front toutes ces questions. Plus modestement ils se donnent comme objectif, dans l'avant-propos, d'apporter «une contribution à l'étude d'une partie du champ culturel dont les trois qualificatifs sont: populaire, urbain et non discursif» (p. 14). On conviendra que la démonstration est courte et la mise en contexte socio-économique, rapide. Si l'histoire du parc Sohmer est bien située dans une perspective internationale (chapitre 1), et décrite avec force détails au chapitre 2 , on reste néanmoins sur sa faim, de par l'absence d'une véritable perspective d'ensemble sur l'histoire de la culture populaire au Québec à cette période, que ne viennent certes pas combler les quelques pages sur «les loisirs à Montréal avant l'ouverture du parc Sohmer» (p. 29-34).

On pourrait parler plutôt d'une contribution significative à la constitution patiente d'une information de base sur la culture urbaine au $19 \mathrm{e}$ siècle, recherche en grande partie tributaire des journaux d'époque et de quelques documents d'archives ou personnels.

C'est ainsi qu'à la suite de l'historique du parc, dans les premiers chapitres, l'ouvrage s'attarde par la suite à la programmation (chapitre 3), dont on distingue quatre phases principales, des concerts musicaux classiques à une diversification vers les programmes de variété, les attractions, les vaudevilles et les spectacles populaires. Un chapitre (chapitre 4) porte d'ailleurs sur le vaudeville et les spectacles de variété, chapitre qu'on aurait intérêt à rapprocher des études sur le théâtre populaire et le burlesque: les publics d'aujourd'hui ont peut-être oublié que beaucoup de personnages que l'on retrouve encore de nos jours ont en quelque sorte trouvé leur terrain d'accueil dans de tels lieux de divertissements populaires de la fin du siècle dernier: musiciens en plein air, imitateurs, magiciens, danseurs, équilibristes, jongleurs, ventriloques, cyclistes, contorsionnistes, hommes forts, nains et manchots! 
Un dernier chapitre porte sur l'utilisation du parc Sohmer pour les fêtes patriotiques, les assemblées politiques (Laurier, on le sait y est allé à quelques reprises), les rassemblements d'associations professionnelles, etc. «Le parc Sohmer fut la première manifestation durable de l'introduction du capitalisme commercial dans les domaines de la culture et du divertissement à Montréal. C'est là sa nouveauté globale la plus radicale», lit-on en conclusion. On y fait référence à l'avènement des journaux populaires, à l'avènement prochain d'une société dite de consommation, au développement des parcs urbains dans les pays occidentaux de l'époque, aux lieux de rassemblements populaires.

Il s'agit sans contexte d'un ouvrage bien documenté; nous savons la patience et la minutie qu'exigent de telles contributions, la longueur de temps, la constance dans la recherche qu'elles supposent. Il faut remercier Yvan Lamonde et Raymond Montpetit de nous avoir livré le résultat de leurs efforts. Si le lecteur demeure sur sa faim, ce n'est pas à cause de l'intérêt du contenu, ce n'est pas non plus par manque d'information détaillée; c'est parce qu'il y manque une mise en perspective plus approfondie, une vision plus globale des changements culturels alors en cause. 